\title{
Optimisation of FSP process parameters of surface composites using GRA and Taguchi approach \\ DOI : 10.36909/jer.ICCEMME.15689
}

Ravi Butola ${ }^{1 *}$, Ravi Kumar ${ }^{1}$, Naman Choudhary ${ }^{1}$, Mohammad Zubair ${ }^{1}$, Shashi Prakash

Dwivedi $^{2}$

${ }^{1}$ Department of Mechanical Engineering, Delhi Technological University, Delhi 110042, India

${ }^{2}$ Department of Mechanical Engineering, GL Bajaj Institute of Technology and Management, Greater Noida, Uttar Pradesh 201306, India

*Email: ravibutola33855@gmail.com; Corresponding Author.

\begin{abstract}
Friction stir processing (FSP) of Al7075-T6 and Boron Carbide $\left(B_{4} C\right)$ nanoparticles as reinforcement were performed adopting Taguchi's $L_{9}$ orthogonal array. Optimisation of parameters which are transverse speed (TS), tool rotational speed (TRS), and tool pin profile (TP) based on residual stress and microhardness was done using Taguchi and Grey Relational Analysis (GRA). Result showed that minimum compressive residual stress and maximum microhardness were obtained at TS of $40 \mathrm{~mm} / \mathrm{min}$, TRS of $1200 \mathrm{rpm}$, and square tool pin profile. Analysis of variance showed that TP+TS with $49.63 \%$ contribution is the most significant factor to influence residual stress and microhardness.
\end{abstract}

Keywords: friction stir processing; GRA; optimisation; residual stress; Taguchi.

\section{INTRODUCTION}

Friction stir processing (FSP) is a quite new technique that is utilized to change certain properties of metal and it involves extreme plastic deformation. The process involves the insertion of a tool forcibly into the workpiece. Then due to the rotation of the tool, a stirring motion is created and it is pushed across the workpiece. During FSP, one side is such that the course of traverse and tool rotation is identical, and hence this is the forward-moving side. Meanwhile, the remaining side is the receding side. Butola et al., (2019) worked on optimizing the aluminum surface composite using the Taguchi method. Taguchi $\mathrm{L}_{9}$ orthogonal array was 
utilized with three levels having three factors. Chaudhary et al., (2018) observed that lightweight metals like Aluminium having low strength, exhibited a good increment in the material properties after friction stir processing due to fine particle structure (Mavhungu et al., 2016 \& Gangil et al., 2017). The geometry of the tool such as tool pin dimensions, shoulder diameter affects heat generation rate, flow, and proper mixing of material (Mahmoud et al., 2009). Bernal et al., (2016) performed the friction stir processing on Al-Mg alloys with different tool geometry. It was found that a tool having a larger shoulder diameter generates high heat. Tyagi et al., (2020) premeditated the mechanical properties of composite reinforced with ceramic along with aloe vera. EDS analysis was done to observe the formation of the oxide layer. Butola et al., (2020) considered the material properties of a self-assembled monolayer of $\mathrm{B}_{4} \mathrm{C}$ and found an increment in hardness. Kumar et al., (2020) \& Murthy et al., (2019) supported the optimisation of FSP parameters of aluminum-based alloy for higher tensile strength using the Taguchi technique. Ahmadkhaniha et al., (2015) resolute the best amalgamation of process parameters that impact the hardness of FSPed unadulterated Mg by using Taguchi approach. Bayazidet al., (2015) conducted a study to probe the effect of friction stir welding variables on properties and microstructure of welded joints of Al6063 and Al7075 alloys by utilizing the Taguchi method and ANOVA analysis. Rathee et al., (2016) optimized the process parameters by utilizing Taguchi L9 orthogonal array to obtain the supreme hardness of AA6061/SiC exterior composite produced by FSP. Abhishek et al., (2019) analyzed the residual stress in Al6061-Graphene FSPed composite and observed the uneven distribution of residual stress in the composite due to the irregular distribution of graphene. In the study by Zhang et al., (2018) the longitudinal residual stresses on the aluminum and copper side were tensile and compressive, as aluminum has an inferior Young's modulus as compared to copper. Butola et al., (2021) \& Butola et al., (2020) observed and compared the residual stress developed on the FSP tool pin during the fabrication process. It was found with more fabrication operation, the nature of stress changed. 
There was a lack of studies where optimisation of the FSP process was done using Taguchi and GRA both where the response variables were residual stress (that too compressive, due to FSP) and microhardness. So, in the present study, we try to accomplish the same after performing a series of experiments using the structure of Taguchi approach.

\section{EXPERIMENTAL METHODS}

\section{Materials and methodology}

In this present investigation industrially accessible aluminum alloy A17075-T6 plate of size 200 $\times 80 \times 6 \mathrm{~mm}$ was used as base metal with $B_{4} C$ particles as reinforcement material. $B_{4} C$ was used because of its chemical and thermal stability. Moreover, it has a more hardness and lower density as related to $\mathrm{SiC}$ and $\mathrm{Al}_{2} \mathrm{O}_{3}$.

The FSP was performed with a groove of $160 \times 2 \times 1.5 \mathrm{~mm}$ on the base plate of size $200 \times 80$ $\times 6 \mathrm{~mm}$ to fill the $B_{4} C$ particles. The FSP arrangement used in this work is shown in Fig. 1(a) and the pictorial depiction of the FSP process is shown in Fig. 1(b). The shoulder diameter and pin length of each tool were $19.95 \mathrm{~mm} \& 3 \mathrm{~mm}$ while the total dimension of the tool was 117 $\mathrm{mm}$.

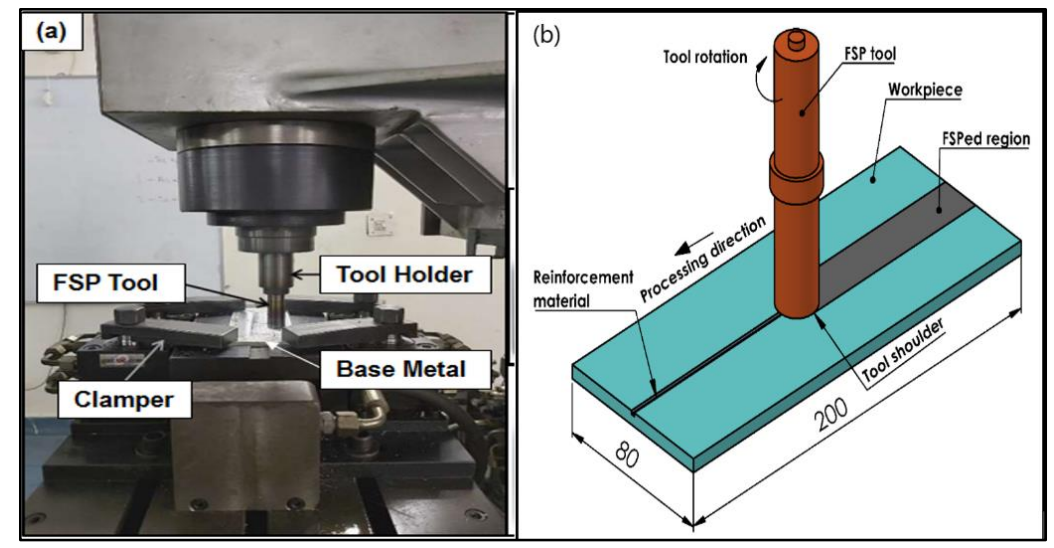

Figure 1 (a) FSP set up (b) Pictorial representation of FSP

Residual stress was determined using a non-destructive methodology i.e., X-ray diffraction based on $\cos \alpha$ method. This technique measures the strain in the metal's atomic crystal and then calculate the residual stress based on strain measurement. The strain can be measured by accurately measuring the various radii from the center of the produced Debye-Scherrer ring. 
As depicted in Fig. 2(a) set of four strains $\varepsilon_{\alpha}, \varepsilon_{\pi+\alpha}, \varepsilon_{-\alpha}, \varepsilon_{\pi-\alpha}$ are calculated from the Debye ring for each value of $\alpha$ which is angle on Debye ring. The shear stress $\boldsymbol{\tau}(\mathrm{xy})$ and normal stress $\boldsymbol{\sigma}(\mathrm{x})$ are calculated by introducing the parameters $a_{1}$ and $a_{2}$ as depicted below:

$$
\begin{gathered}
a_{1}=\frac{1}{2}\left[\left(\varepsilon_{\alpha}-\varepsilon_{\pi+\alpha}\right)+\left(\varepsilon_{-\alpha}-\varepsilon_{\pi-\alpha}\right)\right] \\
a_{2}=\frac{1}{2}\left[\left(\varepsilon_{\alpha}-\varepsilon_{\pi+\alpha}\right)-\left(\varepsilon_{-\alpha}-\varepsilon_{\pi-\alpha}\right)\right] \\
\sigma(\mathrm{x})=-\frac{E}{1+v} \frac{1}{\sin 2 \eta} \frac{1}{\sin 2 \psi_{o}}\left(\frac{\partial a_{1}}{\partial \cos \alpha}\right) \\
\boldsymbol{\tau}(\mathrm{xy})=-\frac{E}{2(1+v)} \frac{1}{\sin 2 \eta} \frac{1}{\sin 2 \psi_{o}}\left(\frac{\partial a_{2}}{\partial \sin \alpha}\right)
\end{gathered}
$$

A mini portable Pulsetec $\mu-X 360$ n analyzer was used as shown in Fig. 2(b) was used to measure residual stress.

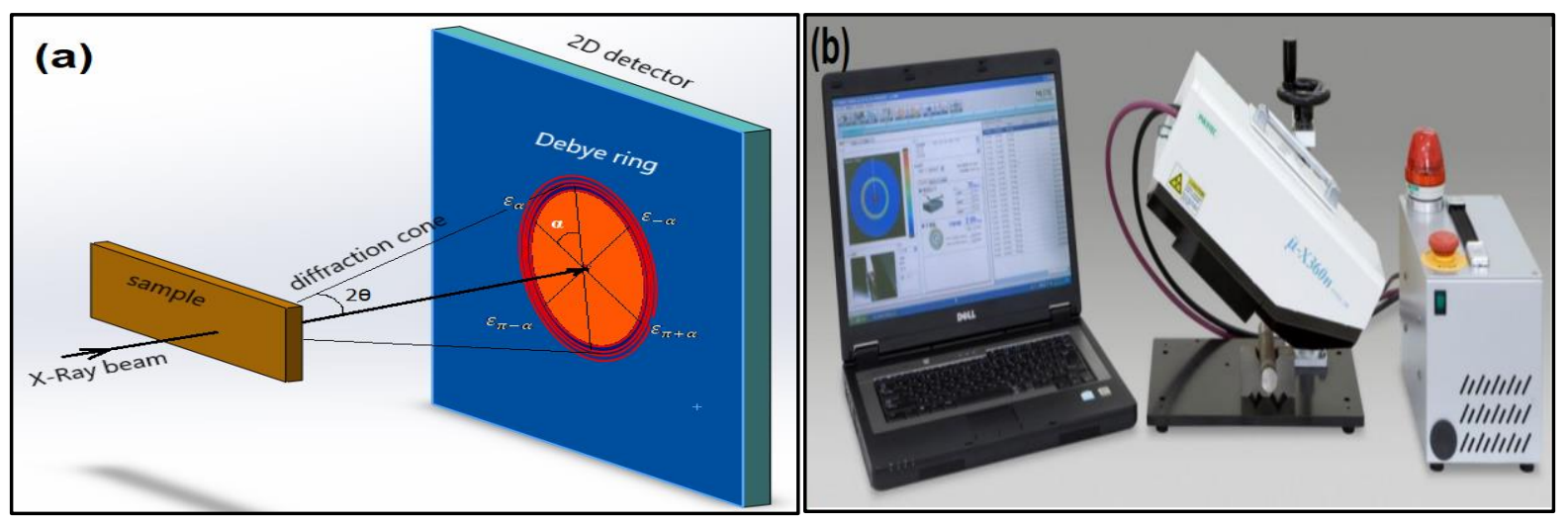

Figure 2(a) Strain measurement from Debye ring (b) Pulsetec $\mu X-360$ n stress analyser set up

\section{Strategy of the experiment using Taguchi technique}

The number of trials was determined via the Taguchi technique. The Taguchi technique enhances process performance with the least number of experiments (Jitender et al., 2016). The Taguchi design is to find the best values of the unbiased function in industrial processes (Varun et al., 2016). Linked to traditional investigational designs, the Taguchi technique makes use of an unusual design of orthogonal array to inspect the quality features through a slight set of experiments. The tentative outcomes are then converted into $\mathrm{S} / \mathrm{N}$ ratios to assess performance appearances. So, the Taguchi technique quintessence on the effects of differences on quality 
characteristics, somewhat than on the means. That is, the Taguchi technique makes the process presentation insensitive to the discrepancies of uncontrollable noise issues. The optimal parameter settings are then found by carrying out the parameter design. With knowledge of the the number of parameters and number of levels, the appropriate orthogonal array can be nominated. Here, the value of TS is kept constant for a particular TP i.e., 40, 50, and $60 \mathrm{~mm} / \mathrm{min}$ for square, triangular and circular respectively. So, the combination of both TS and TP has the same effect during FSP and hence TS+TP is taken as a single parameter or factor. The structure of the L9 Array with two factors and three-level was used.

\section{Process parameters and responses}

Tierce parameters are Transverse speed (TS), Tool pin profile (TP), and Tool Rotational speed (TRS) with three levels in each specimen. Exactly the observation standards are Residual Stress and microhardness. The levels and range of parameters are depicted in Table 1.

Table 1. Process parameters levels and range

\begin{tabular}{|c|c|c|c|c|}
\hline Process & Unit & \multicolumn{3}{|c|}{ Level } \\
\hline Parameters & & $\mathbf{1}$ & $\mathbf{2}$ & $\mathbf{3}$ \\
\hline TRS & rpm & 1000 & 1200 & 1400 \\
\hline TS & $\mathrm{mm} / \mathrm{min}$ & 40 & 50 & 60 \\
\hline TP & - & Square & Triangular & Circular \\
\hline
\end{tabular}

\section{RESULTS AND DISCUSSION}

\section{Residual Stress}

The residual stresses are produced because of the rapid cooling rate and the large thermal gradient during the FSP (Shokrieh et al., 2014). The investigation revealed the compressive residual stress of $86 \mathrm{MPa}$ in magnitude on the parent metal while the value of residual stress on the fabricated composite is quite small as related to the parent metal. The residual stress on all samples was found to be compressive and depicted in Table 2. The least value of compressive 
residual stress (6 MPa) was found at transverse speed (TS) of $40 \mathrm{~mm} / \mathrm{min}$, tool rotational speed (TRS) of $1200 \mathrm{rpm}$, and tool having a square-shaped pin. The residual stresses proofs to be helpful or damaging, depending on whether the nature of stress in the component is compressive or tensile. Generally, the presence of tensile residual stresses can lead to failure or distortion while compressive stresses are generally beneficial as they reduce the effect of applied tensile stresses. In Fig. 3(a) for base metal, the variation of intensity around the circumference of the Debye ring is large and there is a spotty distribution because of coarse grains. The irregularity in the intensity was reduced in Fig. 3(b) for the FSPed composite sample suggesting some grain refinement after friction stir processing.
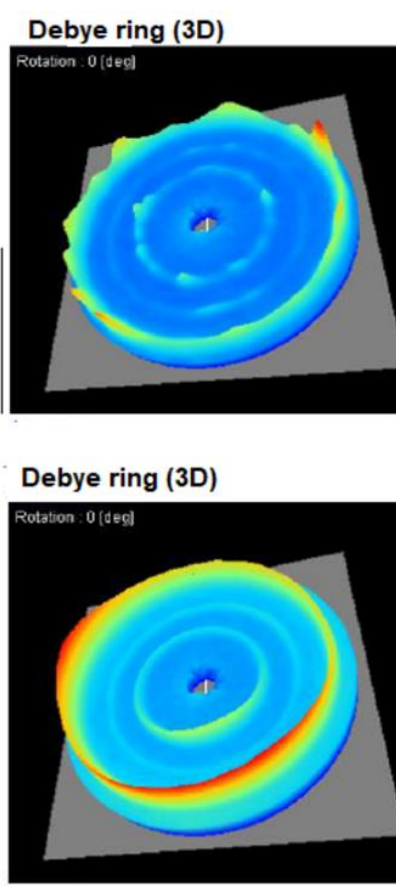

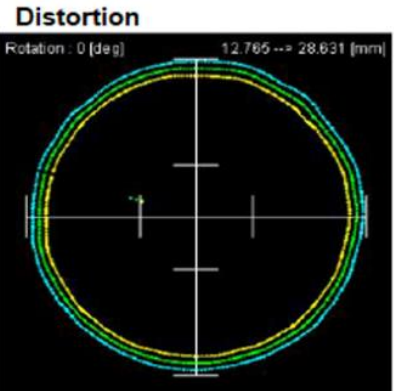

(a)

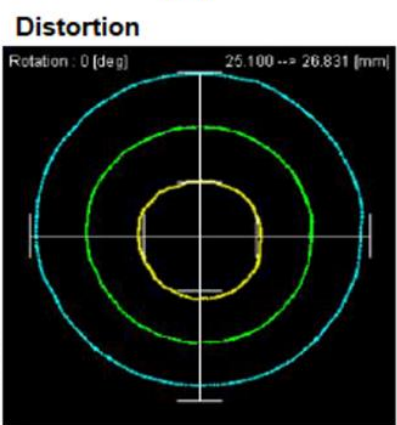

(b)
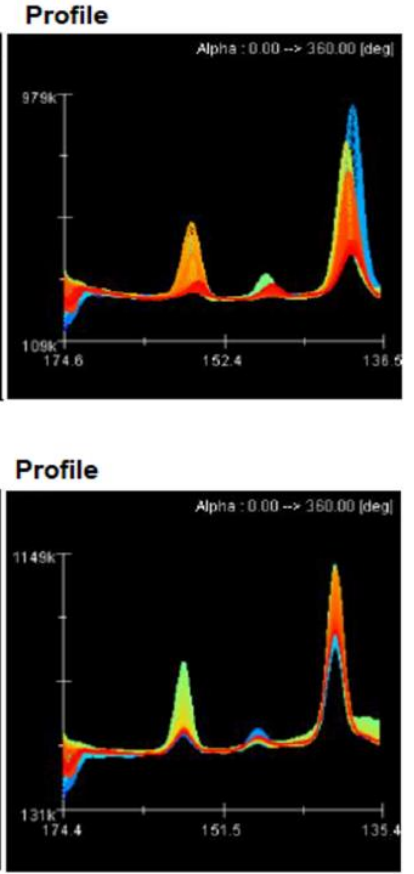

Figure 3 Debye ring (3D), distortion ring, residual stress profile (a) base metal AA7075 (b)

FSPed sample no. 2

\section{Microhardness}

Microhardness values were obtained on the samples after polishing and etching the surfaces. The experimental values of microhardness of the fabricated composites are presented in Table 2 after the FSP of the material. The combination of $B_{4} C$ elements in the metal atmosphere leads to a growth in the value of microhardness. The changes taking place in the microstructure 
during the FSP process led to an increase in microhardness value. Certain mechanisms explain the increase in microhardness like Orowan strengthening. Since the reinforcement particles fragmented during the FSP process, it reduced the distance between particles. This decrement in interparticle spacing explains the enhanced microhardness because of increased interaction between particle and matrix.

\section{Optimisation process}

A grey-based technique has been pragmatic to value residual stress and microhardness in order to augment the FSP process parameters. Rendering to the primary stage of the technique, altogether the investigational figures have been standardized in the series 0 to 1 (Liu et al., 2011 \& Kasman et al., 2013). Magamai et al., (2018) used the equations used over here in this study. Data classification for microhardness values of FSP MMCs were taken as 'larger the better' performance features. In the interim, minimization of residual stress was done since a high amount of residual stress is not good and may lead to failure so; it was taken as 'smaller the better'. The standardization is done for 'larger the better using formula given in Equation (5) and for 'smaller the better' formula is given in Equation (6).

$$
\begin{aligned}
x_{i}^{*}(k) & =\frac{x_{i}(k)-\min x_{i}(k)}{\max x_{i}(k)-\min x_{i}(k)} \\
x_{i}^{*}(k) & =\frac{\max x_{i}(k)-x_{i}(k)}{\max x_{i}(k)-\min x_{i}(k)}
\end{aligned}
$$

Here $x_{i}^{*}(k)$ is produced by grey relation, $\min x_{i}(k)$ signifies the least rate of $x_{i}(k)$ for the retort and $\max x_{i}(k)$ depicts the main value of $x_{i}(k)$ for the $k_{t h}$ retort. Here, $i$ ranges from 1 to the number of trials and $k$ has the array of 1 to the number of outputs. After scheming standardized values, the grey relational coefficients $(\mathrm{GRC}) \xi_{i}(k)$ were planned using Equation (7)

$$
\xi_{i}(k)=\frac{\Delta_{\min }+\zeta \cdot \Delta_{\min }}{\Delta_{0 i(k)}+\zeta . \Delta_{\max }}
$$

Here $\Delta_{0 i(k)}=\left|x_{0}^{*}(k)-x_{i}^{*}(k)\right|$ denotes the deviation order of the comparability arrangement 
$x_{i}^{*}(k)$ and the reference order $x_{i}^{*}(k) \cdot \Delta_{\min }(k)$ and $\Delta_{\max }(k)$ are the least and major values of $\Delta_{0 i(k)}$ and $\zeta$ is the distinctive coefficient equivalent to 0.5 . The grey relational coefficient of every trial in L9 orthogonal array. Grey relational grades (GRG) were calculated after finding the GRCs using Equation (8).

$$
\gamma_{i}=\frac{1}{n} \sum_{k=1}^{n} \xi_{i}(k)
$$

Where, $\gamma_{i}$ is the GRG for the $i_{t h}$ trial besides $n$ is the sum of performance features. The ranking and grey relational grades of the output performance are shown in Table 2.

Table 2 Experimental and Standardized Values of Responses

\begin{tabular}{|c|c|c|c|c|c|c|}
\hline $\begin{array}{c}\text { Exp } \\
\text { No }\end{array}$ & \multicolumn{2}{|c|}{ Experimental Values } & \multicolumn{2}{c|}{ Normalized Values } & GRG & Rank \\
\cline { 1 - 6 } & Avg. Residual Stress & Microhard & Avg. Residual & Microhard & & \\
\hline 1 & 23 & 179 & 0.261 & 0.476 & 0.446 & 6 \\
\hline 2 & 6 & 190 & 1.000 & 1.000 & 1.000 & 1 \\
\hline 3 & 17 & 187 & 0.522 & 0.857 & 0.644 & 2 \\
\hline 4 & 15 & 170 & 0.609 & 0.048 & 0.453 & 5 \\
\hline 5 & 22 & 185 & 0.304 & 0.762 & 0.548 & 3 \\
\hline 6 & 28 & 182 & 0.043 & 0.619 & 0.455 & 4 \\
\hline 7 & 29 & 169 & 0.087 & 0.000 & 0.344 & 9 \\
\hline 8 & 19 & 173 & 0.000 & 0.190 & 0.358 & 8 \\
\hline 9 & & 171 & 0.435 & 0.095 & 0.413 & 7 \\
\hline
\end{tabular}

Taguchi Analysis

It is apparent from Figure 4, as TS rises $\mathrm{S} / \mathrm{N}$ ratio declines. Now when TRS increases $\mathrm{S} / \mathrm{N}$ ratio also increases and then decreases. It can be assessed from the graph that TP and TS at level 1 and TRS at level 2 will offer the optimum mixture values of outputs (residual stress and microhardness) concurrently. For optimal values, the peak $\mathrm{S} / \mathrm{N}$ ratio is considered. 


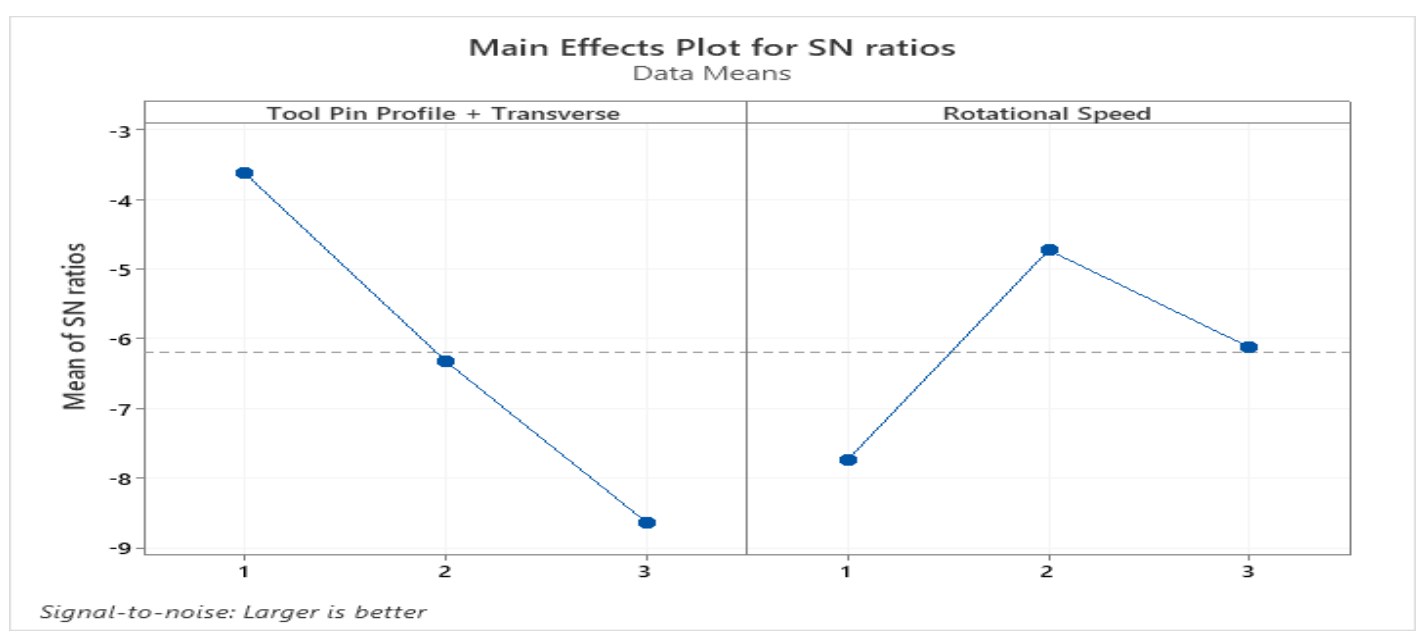

Figure 4 S/N ratio of GRG (Min. RS)

Table 3 Analysis of Variance (ANOVA) for GRG

\begin{tabular}{|c|c|c|c|c|c|c|c|}
\hline Source & DF & Seq SS & Contribution & Adj SS & Adj MS & F-Value & P-Value \\
\hline TP + TS & 2 & 0.16370 & $49.63 \%$ & 0.16370 & 0.08185 & 3.56 & 0.129 \\
\hline TRS & 2 & 0.07414 & $22.48 \%$ & 0.07414 & 0.03707 & 1.61 & 0.307 \\
\hline Error & 4 & 0.09199 & $27.89 \%$ & 0.09199 & 0.02300 & & \\
\hline Total & 8 & 0.32983 & $100.00 \%$ & & & & \\
\hline
\end{tabular}

From Table 3, we can see the percentage contribution of factors which is $49.63 \%$ for TP + TS and $22.48 \%$ for TRS meaning that TP+TS is the most influencing factor. The improved Taguchi outcome was predicted by the Minitab 19 package which is exemplified in Table 4. It was detected that TP of the square, TS of $40 \mathrm{~mm} / \mathrm{min}$, and TRS of $1200 \mathrm{rpm}$ will provide the optimum combination of residual stress and microhardness.

Table 4 Factor Level for Prediction

\begin{tabular}{|c|c|c|c|c|}
\hline TP & TS & TRS & S/N ratio & GRG \\
\hline Square pin profile & $40 \mathrm{~mm} / \mathrm{min}$ & $1200 \mathrm{rpm}$ & -2.14417 & 0.814136 \\
\hline
\end{tabular}

\section{CONCLUSION}

In the current work, Taguchi $\mathrm{L}_{9}$ orthogonal array was utilized to perform experiments and for optimization through grey relational analysis. The process parameters were optimized through 
Taguchi-GRA using grey relational grade. After which Taguchi Analysis was also done so that we can predict optimum parameters for maximum GRG. Minimization of residual stress was done as lower the stress, longer the tool life, and less tool fatigue. While maximization of microhardness was done which increases the tool life. The optimal values through GRA were found to be square TP, TS of $40 \mathrm{~mm} / \mathrm{min}$, and TRS of $1200 \mathrm{rpm}$. The predicted optimal values of process parameters after applying Taguchi analysis for maximizing GRG as response variable was found to be TS as $40 \mathrm{~mm} / \mathrm{min}$, TP of a square shape, and TRS of $1200 \mathrm{rpm}$ giving GRG as 0.814 . The offerings of TRS and TS+TP in disturbing the GRG significance are $22.48 \%$ and $49.63 \%$ correspondingly, as confirmed by ANOVA.

\section{REFERENCES}

Butola, R., Singari, R. M., \& Murtaza, Q. 2019. Fabrication and optimization of AA7075 matrix surface composites using Taguchi technique via Friction stir processing (FSP). Engineering Research Express 1: 025015.

Chaudhary, A., Kumar Dev, A., Goel, A., Butola, R., \& Ranganath, M. S. 2018. The Mechanical Properties of Different alloys in friction stir processing: A Review. Materials Today: Proceedings. 5(2): 5553-5562.

Mavhungu, S. T., Akinlabi, E. T., Onitiri, M. A., \& Varachia, F. M. 2017. Aluminum Matrix Composites for Industrial Use: Advances and Trends. Procedia Manufacturing. 7: 178-182.

Gangil, N., Siddiquee, A. N., \& Maheshwari, S. 2017. Aluminium based in-situ composite fabrication through friction stir processing: A review. Journal of Alloys and Compounds. 715: 91-104.

Mahmoud, E. R. I., Takahashi, M., Shibayanagi, T., \& Ikeuchi, K. 2009. Effect of friction stir processing tool probe on fabrication of $\mathrm{SiC}$ particle reinforced composite on aluminium surface. Science and Technology of Welding and Joining. 14(5): 413-425.

García-Bernal, M. A., Mishra, R. S., Verma, R., \& Hernández-Silva, D. 2016. Influence of friction stir processing tool design on microstructure and superplastic behavior of Al-Mg alloys. 
Materials Science and Engineering: A. 670: 9-16.

Tyagi, L., Butola, R., \& Jha, A. K. 2020. Mechanical and tribological properties of AA7075T6 metal matrix composite reinforced with ceramic particles and aloevera ash via Friction stir processing. Materials Research Express. 7(6): 066526.

Butola, R., Singari, R. M., \& Murtaza, Q. 2020. Mechanical and wear behaviour of Friction stir processed surface composite through Self-Assembled Monolayer Technique, Surf. Topogr: Metrol. Prop. 8(4): 045007.

Kumar D., Kumar J. 2020. Optimisation of Parameters in Friction Stir Welding of AA6101T6 by Taguchi Approach. In: Venkata Rao R., Taler J. (eds) Advanced Engineering Optimisation Through Intelligent Techniques. Advances in Intelligent Systems and Computing. Springer. 949. Pp. 361-370.

Veeresh Murthy, S. Dileep Kumar, K.K. Saju, B.M. Rajaprakash \& R. Rajashekar. 2019. Optimisation of Friction Stir Processing parameters for manufacturing silicon carbide reinforced Al 7075-T651 surface composite. Materials Today: Proceedings. 18(7): 4549-4555. D. Ahmadkhaniha, M. Heydarzadeh Sohi, A. Zarei-Hanzaki, S.M. Bayazid \& M. Saba. 2015. Taguchi optimisation of process parameters in friction stir processing of pure $\mathrm{Mg}$, Journal of Magnesium and Alloys. 3(2): 168-172.

Bayazid, S. M., Farhangi, H., \& Ghahramani, A. 2015. Investigation of Friction Stir Welding Parameters of 6063-7075 Aluminum Alloys by Taguchi Method. Procedia Materials Science. 11: 6-11.

Rathee, S., Maheshwari, S., Noor Siddiquee, A., Srivastava, M., \& Kumar Sharma, S. 2016. Process parameters optimisation for enhanced microhardness of AA 6061/ SiC surface composites fabricated via Friction Stir Processing (FSP). Materials Today Proceedings. 3(10): $4151-4156$.

Abhishek Sharma, Vyas Mani Sharma, Baidehish Sahoo, SurjyaKanta Pal \& Jinu Paul. 2019. Effect of multiple micro channel reinforcement filling strategy on Al6061- graphene 
nanocomposite fabricated through friction stir processing. Journal of Manufacturing Processes. 37: 53-70.

Chengcong Zhang \& Amir A. Shirzadi. 2018. Measurement of residual stresses in dissimilar friction stir-welded aluminium and copper plates using the contour method. Science and Technology of Welding and Joining. 23: 394-399.

Butola, R., Choudhary, Naman., Kumar, Ravi., Mouria, Pradeep Kumar., Zubair, Mohammad., \& Singari, R.M. 2021. Measurement of residual stress on H13 tool steel during machining for fabrication of FSW/FSP tool pins. Materials Today: Proceedings.

Butola, R., Singari, R. M., \& Murtaza, Q. 2020. An experimental and simulation validation of residual stress measurement for manufacturing of friction stir processing tool. Indian Journal of Engineering \& Materials Sciences. 27: 826-836.

Kundu, Jitender \& Singh, Hari. 2016. Friction stir welding: multi-response optimisation using Taguchi-based GRA. Production \& Manufacturing Research.4: 228-241.

Varun Kumar, A., Balasrinivasan, M., \& Dulkiflee, M. 2016. Grey Relational Analysis and Taguchi Method for the Parametric Optimisation of Single Pass Friction Stir Welded Aluminum Alloy 7075-T6 Joints. Applied Mechanics and Materials. 852: 331-336.

Shokrieh, M. M., \& Ghanei Mohammadi, A. R. 2014. The importance of measuring residual stresses in composite materials. Residual Stresses in Composite Materials. 3-14

S. Liu, J. Forrest \& Y. Yang. 2011. A brief introduction to grey systems theory. Proceedings of 2011 IEEE International Conference on Grey Systems and Intelligent Services. Pp. 1-9.

Kasman, Ş. 2013. Multi-response optimisation using the Taguchi-based grey relational analysis: a case study for dissimilar friction stir butt welding of AA6082-T6/AA5754H111. Int. J Adv. Manuf. Technol. 68: 795-804.

Magamai Radj, B., \& Senthivelan, T. 2018. Analysis of mechanical properties on friction stir welded magnesium alloy by applying Taguchi Grey based approach, Materials Today: Proceedings. 5(2): 8025-8032. 